\title{
Effect of Gold Nanoparticles on the Photocatalytic and Photoelectrochemical Performance of $\mathrm{Au}$ Modified $\mathrm{BiVO}_{4}$
}

\author{
Mingce Long ${ }^{1, *}, \quad$ Jingjing Jiang ${ }^{1}, \quad$ Yan $\mathrm{Li}^{1}$, Ruqiong $\mathrm{Cao}^{1}$, Liying Zhang ${ }^{2}$, Weimin Cai ${ }^{1}$
}

(Receive 13 August 2011; accepted 18 August 2011; published online 22 September 2011.)

\begin{abstract}
An efficient visible light driven photocatalyst, gold nanoparticles (NPs) modified $\mathrm{BiVO}_{4}(\mathrm{Au}$ $\mathrm{BiVO}_{4}$ ), has been synthesized by deposition-precipitation with urea method. $\mathrm{Au} / \mathrm{BiVO}_{4}$ exhibits enhanced photocatalytic activity for phenol degradation under $\lambda>400 \mathrm{~nm}$ irradiation but negligible activity under $\lambda>535 \mathrm{~nm}$, indicating that the surface plasmon resonance (SPR) effect is too weak for organic photodegradation. According to the photoelectrochemical results of the porous powder electrodes of $\mathrm{BiVO}_{4}$ and $\mathrm{Au} / \mathrm{BiVO}_{4}$, the $\mathrm{SPR}$ effect of Au NPs has been assessed. The role of Au NPs as electron sinks or sources, which is controllable by incident photon energy and applied potentials, has been discussed.
\end{abstract}

Keywords: Visible light; Gold nanoparticles; $\mathrm{BiVO}_{4}$; Surface plasmonic resonance; Photocurrent

Citation: Mingce Long, Jingjing Jiang, Yan Li, Ruqiong Cao, Liying Zhang and Weimin Cai, "Effect of Gold Nanoparticles on the Photocatalytic and Photoelectrochemical Performance of Au Modified BiVO," Nano-Micro Lett. 3 (3), 171-177 (2011). http://dx.doi.org/10.3786/nml.v3i3.p171-177

\section{Introduction}

Photocatalysis is promising to be an efficient way to convert and utilize solar energy. Much work has been done to develop novel photocatalysts with desirable photocatalytic performance, such as a wide range of optical response accompanying with high efficiency and long term stability [1-3]. Bismuth vanadate $\left(\mathrm{BiVO}_{4}\right)$ with monoclinic scheelite structure $\left(\mathrm{E}_{\mathrm{g}} \sim 2.4 \mathrm{eV}\right)$ exhibits a strong potential on water splitting and organic pollutants decomposition under visible light irradiation [4-6]. Therefore it has become to be another popular photocatalyst. However, $\mathrm{BiVO}_{4}$ always has a low specific area and shows only limited photocatalytic activity. Fabricating a composite with a variety of heterojunctions is an important approach to promote the separation of photogenerated carriers, so as to enhance the photocatalytic performance dramatically. As we know, surface modified photocatalyst with noble metals such as $\mathrm{Ag}, \mathrm{Au}, \mathrm{Pt}$, etc. is one of the most frequently applied heterojuctions [7-9]. These metal particles can serve as sinks for photoinduced electrons and promote interface charge-transfer process [10].

On the other hand, nanoparticles (NPs) of noble metals have strong absorption in the range of visible light due to the well-known surface plasmon resonance (SPR) effect. The aim of photocatalysis is to utilize photon energy initiating electron transfer and resulting in chemical reactions. SPR effect happens to be a mergence of photon and electron at nanoscale dimensions [11]. With the increasing attention on the SPR effect, the role of gold nanoparticles on the photocatalytic degradation of organic pollutants has been reconsidered recently. The charge transfer of photoexcited SPR electrons from the gold NPs to the conduction band of $\mathrm{TiO}_{2}$ has been observed indirectly by plasmon-induced photoelectrochemistry [12-14] or directly by the femtosecond transient absorption spectroscopy [15]. Re-

\footnotetext{
${ }^{1}$ School of Environmental Science and Engineering, Shanghai Jiao Tong University, Dongchuan Road 800, Shanghai 200240, China

${ }^{2}$ Key Laboratory for Thin Film and Microfabrication of the Ministry of Education, Research Institute of Micro/Nano Science and Technology, Shanghai JiaoTong University, Shanghai, 200240, China

*Corresponding author. E-mail: long_mc@sjtu.edu.cn
} 
cently the visible-light driven photocatalytic reactions originated from the SPR effect of Au NPs has been verified [16-18]. Several visible light plasmonic photocatalysts with noble metal NPs, such as $\mathrm{Ag} / \mathrm{AgCl}$ [19], $\mathrm{Ag} / \mathrm{AgI} / \mathrm{Al}_{2} \mathrm{O}_{3}$ [20], $\mathrm{Au} / \mathrm{TiO}_{2}[17,18]$, etc., have been developed and attracted considerable attention.

Compared with silver, metallic gold is a more stable noble metal with extraordinarily high activity in many catalytic reactions, and is widely employed as a catalyst for $\mathrm{CO}$ oxidation at low temperatures [21]. Recently, the effect of Au NPs SPR on photocatalytic reactions has been stressed. The action spectrum of the photocatalytic activity of gold modified $\mathrm{TiO}_{2}$ induced by SPR effect has been reported by Kowalska et al. [17]. However, according to the photoelectrocatalytic tests of $\mathrm{FTO} / \mathrm{WO}_{3} / \mathrm{BiVO}_{4}$ electrode modified with $\mathrm{Au}$ NPs, Chatchai et al. denied the beneficial role of SPR effect for the catalytic activity under visible light irradiation, but only confirmed the promoted charge transfer process after Au NPs deposition [22]. Therefore it is difficult to evaluate the roles of SPR effect and electron sinks during photocatalytic reactions, and it is still a challenge to obtain detailed information on the photogenerated charges transfer process at the interface of Au NPs and photo-response semiconductors. In this contribution, an efficient visible light response photocatalyst, $\mathrm{Au}$ modified $\mathrm{BiVO}_{4}$ has been synthesized by deposition-precipitation with urea method, which is more favorable to produce highly active $\mathrm{Au} / \mathrm{BiVO}_{4}$ with homogeneous Au NPs than the photodeposition technique. According to the photoelectrochemical measurements, photogenerated charge transfer information at the interface of the composite has been analyzed, and the role of $\mathrm{Au}$ NPs under different conditions has been discussed.

\section{Experimental}

Monoclinic $\mathrm{BiVO}_{4}$ powders were prepared according to the description of Kohtani et al. [6]. The preparation of gold modified $\mathrm{BiVO}_{4}\left(\mathrm{Au} / \mathrm{BiVO}_{4}\right)$ was performed by a deposition-precipitation with urea (DP urea) method [23]. Briefly, $1 \mathrm{~g}$ of $\mathrm{BiVO}_{4}$ powders were dispersed into $0.42 \mathrm{M}$ urea solution, then a desirable amount of $\mathrm{HAuCl}_{4}$ aqueous solution was added to make Au contents as $0.25 \mathrm{wt} \%, 0.5 \mathrm{wt} \%, 1 \mathrm{wt} \%$ and $2 \mathrm{wt} \%$ that of $\mathrm{BiVO}_{4}$. The suspension was ultrasonically treated for $15 \mathrm{~min}$, and then continuously stirred under $90^{\circ} \mathrm{C}$ for $4 \mathrm{~h}$ in an airproof condition. The resulting precipitate was collected, washed with deionized water and dried. Finally $\mathrm{Au} / \mathrm{BiVO}_{4}$ is obtained by calcined at $300^{\circ} \mathrm{C}$ for $2 \mathrm{~h}$.

The micrograph and surface morphology of the particles was observed by a high resolution-transmission electron microscopy (HRTEM, JEM100-CX JEOL) and a scanning electron microscope (SEM, FE-SEM FEI SIRION 200). Diffuse reflectance spectra were recorded on a TU-1901 spectrophotometer equipped with a diffuse reflectance accessory (Beijing purkinje general instrument Co., Ltd., China), and the reflectance was converted to $\mathrm{F}\left(\mathrm{R}_{\infty}\right)$ values according to the KubelkaMunk method. X-ray absorption near edge structure (XANES) of Au L $\mathrm{L}_{\mathrm{III}}$ edges were carried out by the X-ray absorption fine structure (XAFS) beamline (BL14W1) at Shanghai Synchrotron Radiation Facility (SSRF) in China.

Phenol degradation was employed to evaluate the photocatalytic activity of the samples. The optical system consists of a $1000 \mathrm{~W}$ xenon lamp and a cutoff filter $(\lambda>400 \mathrm{~nm}) .3 \mathrm{~g} / \mathrm{l}$ catalysts was added into a $50 \mathrm{ml}$ phenol solution $\left(\mathrm{C}_{0}=10 \mathrm{mg} / \mathrm{l}\right)$. Prior to irradiation, the suspension was stirred in dark for 15 min to reach an adsorption equilibrium. Samples were taken at regular time intervals, separated by filtration under reduced pressure and analyzed by spectrophotometric method of the 4-aminoantipyrine at $510 \mathrm{~nm}$ with a UNICO UV2102 spectrometer.

Photoelectrochemical test systems were composed of a CHI 600D Electrochemistry potentiostat, a $500 \mathrm{~W}$ Xenon lamp with or without cutoff filters $(\lambda>400 \mathrm{~nm}$, $535 \mathrm{~nm}$ or $600 \mathrm{~nm}$ ) and a homemade three electrode cell using a platinum as counter electrode, $\mathrm{Ag} / \mathrm{AgCl}$ as reference electrode and $\mathrm{Na}_{2} \mathrm{SO}_{4}(0.5 \mathrm{M})$ as electrolyte. Working electrode was prepared by depositing the suspension of a paste $(1 \mathrm{~g}$ catalyst powder, $2 \mathrm{ml}$ terpineol and $2 \mathrm{ml}$ ethyl cellulose of $10 \mathrm{wt} \%$ ethanolic mixtures) onto a fluorine-doped tin oxide-coated glass (FTO) with doctor-blade coating method and followed with calcination at $500^{\circ} \mathrm{C}$ for $2 \mathrm{~h}$. During measurements, the electrode was pressed against an O-ring of an electrochemical cell with a working area of $0.78 \mathrm{~cm}^{2}$. The dependence of photocurrent on applied potential was measured under various illumination conditions at a sweep rate of $10 \mathrm{mv} / \mathrm{s}$ in a nitrogen purged $\mathrm{Na}_{2} \mathrm{SO}_{4}$ $(0.5 \mathrm{M})$ electrolyte. The working electrodes were irradiated from the back side (substrate/semiconductor interface) in order to minimize the influence of thickness of the semiconductor layer. If not specified, the potential thereafter is versus $\mathrm{Ag} / \mathrm{AgCl}$.

\section{Results and discussion}

Figure 1 shows the microscopy morphology of a typical Au modified $\mathrm{BiVO}_{4}$ particle. The image of Fig. 1(a) demonstrates that the small hetero nano-islands homogeneously disperse over the surface of $\mathrm{BiVO}_{4}$ micro particles. The micrograph shows these nanocrystalline islands of $8 \sim 10 \mathrm{~nm}$. The magnified view of the fringes in the TEM images of Fig. 1(b) and the inset in Fig. 1(b) indicate the existence of a highly crystalline 
gold nanoparticle (well resolved Au (111) crystalline lattices of $0.25 \mathrm{~nm})$.

The color of gold modified $\mathrm{BiVO}_{4}$ is varied from light green to dark green, and the color becomes darker and darker with increases of gold content. Figure 2(A) shows the DRS of pure $\mathrm{BiVO}_{4}$ and gold modified $\mathrm{BiVO}_{4}$. The first band gap absorption edge of gold modified $\mathrm{BiVO}_{4}$ is the same as that of pure $\mathrm{BiVO}_{4}$, about $520 \mathrm{~nm}$, corresponding to the band gap energy of $2.4 \mathrm{eV}$. However, the samples of gold modified $\mathrm{BiVO}_{4}$ have obvious SPR absorption band around $600 \mathrm{~nm}$. The absorption maximum are 608, 618, 619 and $630 \mathrm{~nm}$ for the samples with $0.25,0.5,1$ and $2 \mathrm{wt} \%$ gold content, respectively. Their SPR absorption bands are red shifted obviously comparing with the colloidal gold nanoparticles, whose absorption band is about $520 \mathrm{~nm}$ when they have the same particle sizes [24]. The red shift of SPR absorption bands has also been observed for $\mathrm{Au} / \mathrm{TiO}_{2}$ films [13]. It can be explained by the additional scatterer of the large $\mathrm{BiVO}_{4}$ supporter which has a large refractive index [25] and the formation of an indirect charge transfer band [13]. In addition, the red shift of absorption maximum with increases of gold contents is related with the gold particle sizes. According to the DP urea method, the average particle size of gold would enlarge a little with a higher gold content [23]. This can be supported by the SEM image of 2 wt\% Au/ $\mathrm{BiVO}_{4}$ (S-Fig. 1), in which $\mathrm{Au}$ NPs shows obviously larger sizes with several agglomerated particles. From the DRS results, the absorption intensity is enhanced with increases of the gold content but almost the same for the two samples with $1 \mathrm{wt} \%$ and $2 \mathrm{wt} \%$ gold. Moreover, the SPR bandwidth for $2 \mathrm{wt} \%$ $\mathrm{Au} / \mathrm{BiVO}_{4}$ is enlarged to be $150 \mathrm{~nm}$, more than $20 \mathrm{~nm}$ wider than other samples. The enhanced absorption intensity can be understood by the presence of more and larger gold nanoparticles. However, because of the size effect, the absorption intensity of the sample the $2 \mathrm{wt} \%$ $\mathrm{Au} / \mathrm{BiVO}_{4}$ is not improved and the SPR bandwidth enlarged.

The presence of gold cannot be resolved from the XRD pattern (S-Fig. 2), in which $\mathrm{BiVO}_{4}$ still possesses a monoclinic scheelite structure. This can be attributed to the nanosizes, well dispersion and low contents of gold nanoparticles. The metallic Au has been proofed by the XANES measurements. Figure 2(B) shows the $\mathrm{Au} \mathrm{L} \mathrm{L}_{\mathrm{III}}$ edge XANES spectra of $\mathrm{Au} / \mathrm{BiVO}_{4}$, in comparison with the reference spectra of $\mathrm{Au}_{2} \mathrm{O}_{3}$ and $\mathrm{Au}$ foil. The intensity of the white line (WL), which is the first absorption above the edge in a XANES spectrum,

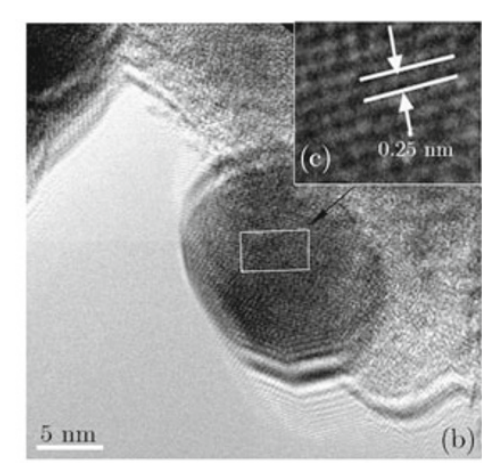

Fig. 1 Representative SEM (a) and HR-TEM image (b) of $1 \mathrm{wt} \% \mathrm{Au} / \mathrm{BiVO}_{4}$. The inset in Fig. 2(b) is the corresponding magnified views of $\mathrm{Au}$ nanocrystalline.
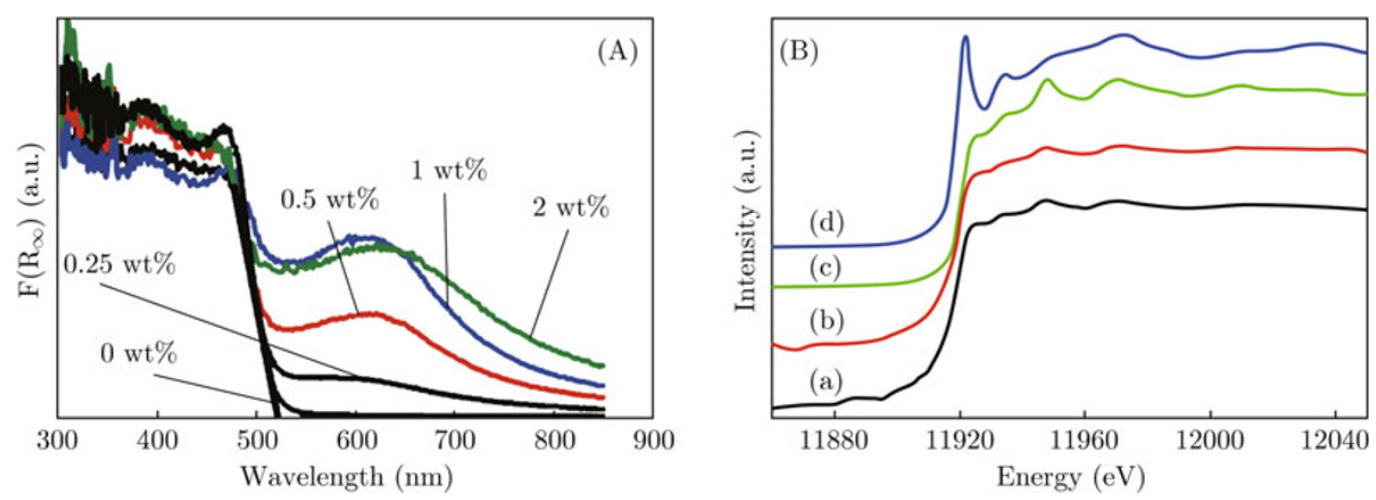

Fig. 2 (A) UV-vis diffuse reflectance spectra of $\mathrm{BiVO}_{4}$ and $\mathrm{Au} / \mathrm{BiVO}_{4}$ and (B) $\mathrm{Au} \mathrm{L}_{\mathrm{III}}$ edge XANES spectra for the 1 wt\% $\mathrm{Au} / \mathrm{BiVO}_{4}$ before (a) and after photocatalytic reaction (b), in comparison with those for the references $\mathrm{Au}_{\text {foil }}(\mathrm{c})$ and $\mathrm{Au}_{2} \mathrm{O}_{3}$ (d), the curves were offset vertically. 
corresponds to the density of the unoccupied d states [21]. According to the correlation between the WL intensity and the oxidation state of $\mathrm{Au}$ in the references, nearly identical intensity of the WL for $\mathrm{Au} / \mathrm{BiVO}_{4}$ and $\mathrm{Au}$ foil confirms that $\mathrm{Au}$ is present as metallic nanoparticles in the samples.

\section{Photocatalytic activity}

The photocatalytic activity of $\mathrm{Au} / \mathrm{BiVO}_{4}$ in phenol degradation under irradiation above $400 \mathrm{~nm}$ (Fig. 3) has been studied. The decrease of phenol concentration in the presence of pure $\mathrm{BiVO}_{4}$ is very small. It can be attributed to the significant recombination of photogenerated carriers on the large particles. The performance can be dramatically improved when loading with gold NPs. Figure 3 also reflects the effect of Au content on the photocatalytic activity. $0.5 \mathrm{wt} \%$ and $1 \mathrm{wt} \%$ $\mathrm{Au} / \mathrm{BiVO}_{4}$ have the close best activity, with a phenol concentration reduction as much as $99 \%$ in $150 \mathrm{~min}$. However, the gold content increased to $2 \%$ would decrease the activity. It can be understood by the two facets. When the noble metal NPs served as electron sinks, higher gold content would form overlapping agglomerates and smother the surface of the main photocatalyst $\mathrm{BiVO}_{4}$ [26]. Moreover, when the Au NPs serve as electron sources with SPR excitation, increasing gold content to $2 \mathrm{wt} \%$ did not enhance the absorption intensity due to the enlarged particle sizes. In addition, from Fig. 2(B) the identical WL intensity of $\mathrm{Au}$ in the $\mathrm{Au} / \mathrm{BiVO}_{4}$ before and after photocatalytic reaction indicates the metallic gold on the $\mathrm{BiVO}_{4}$ is chemical stable and no reoxidation occurs under photocatalytic reaction conditions. The photocatalytic activity of $\mathrm{BiVO}_{4}$ has almost disappeared due to the absorption edge of $\mathrm{BiVO}_{4}$ at about $520 \mathrm{~nm}$. Moreover, upon illumination above $535 \mathrm{~nm}, 1 \mathrm{wt} \% \mathrm{Au} / \mathrm{BiVO}_{4}$ shows negligible phenol degradation activity. The low degradation

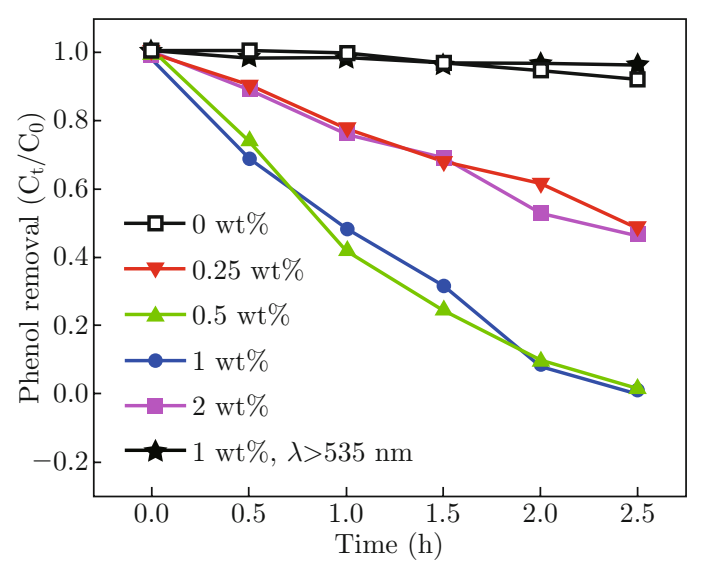

Fig. 3 The decrease of phenol by different photocatalysts as a function of visible light irradiation time $(\lambda>400 \mathrm{~nm}$ or $\lambda>535 \mathrm{~nm})$. efficiency indicates that SPR effect of Au NPs contribute little to the photocatalytic degradation for organic substance.

\section{Photoelectrochemical preformance}

The charge transfer mechanism of the gold modified $\mathrm{BiVO}_{4}$ has been further investigated by photoelectrochemical measurements. Figure 4 is the current densitypotential curves of $\mathrm{BiVO}_{4}$ and $1 \mathrm{wt} \% \mathrm{Au} / \mathrm{BiVO}_{4}$ upon various irradiation conditions with a nitrogen purged electrolyte. Gold NPs modified $\mathrm{BiVO}_{4}$ shows a higher anodic photocurrent under all irradiation conditions, which parallels the enhanced photocatalytic activity. The sharp increase of dark cathodic current below $-0.25 \mathrm{~V}$ vs. $\mathrm{Ag} / \mathrm{AgCl}$ for $\mathrm{Au} / \mathrm{BiVO}_{4}$ indicates that the gold NPs are active centers for electron scavenging and transfer, and promotes the water electrolysis process [27]. Photocurrent onset potential $\left(\mathrm{U}_{\mathrm{on}}\right)$ can be estimated as the quasi Fermi level of semiconductor electrode, which is also corresponding to the position where electrons transfer out. For $\mathrm{BiVO}_{4}$ electrode, the $\mathrm{U}_{\mathrm{on}}$ is independent of the illumination condition, which is around $-0.49 \mathrm{~V}$ vs. $\mathrm{Ag} / \mathrm{AgCl}$, close to our previous reports [28]. However, the $\mathrm{U}_{\text {on }}$ of $\mathrm{Au} / \mathrm{BiVO}_{4}$ is shift negatively upon illumination with low energy. It can be obviously observed from Fig. 4(b) that the $\mathrm{U}_{\text {on }}$ are about $-0.34,-0.38$ and $-0.49 \mathrm{~V}$ vs. $\mathrm{Ag} / \mathrm{AgCl}$ for whole spectrum, $\lambda>400 \mathrm{~nm}$ and $\lambda>535 \mathrm{~nm}$ irradiation, respectively. It is interesting that the $\mathrm{U}_{\text {on }}$ for the $\mathrm{Au} / \mathrm{BiVO}_{4}$ electrode is the same as $\mathrm{BiVO}_{4}$ when illuminated with a $\lambda$ longer than $535 \mathrm{~nm}$, whereas upon the same illumination the photocurrent is almost disappeared for pure $\mathrm{BiVO}_{4}$. Moreover, when illuminated under the former two conditions, there are obvious cathodic photocurrents at a bias more positive than the corresponding $\mathrm{U}_{\mathrm{on}}$. This can be further confirmed by the photocurrent transient curves at a bias of $-0.4 \mathrm{~V}$ vs. $\mathrm{Ag} / \mathrm{AgCl}$ shown in Fig. 5(a). When illuminated with a whole spectrum or $\lambda$ longer than $400 \mathrm{~nm}$, cathodic photocurrents with an initial spike and subsequent decay indicating significant surface recombination can be observed [28-30]. It should be noted that the applied potential is still more positive than the flat band potential of $\mathrm{BiVO}_{4}$. Figure 5(b) shows the photocurrent transients of the $\mathrm{Au} / \mathrm{BiVO}_{4}$ electrodes with various $\mathrm{Au}$ contents upon the illumination $\lambda>600 \mathrm{~nm}$. Obvious anodic photocurrents can be observed upon the illumination with the photon energy lower than the band gap of $\mathrm{BiVO}_{4}$. Moreover, it can be observed that the anodic photocurrents are $0.93,0.46,0.40$ and $0 \mu \mathrm{A} / \mathrm{cm}^{2}$ for the $2 \mathrm{wt} \%, 1 \mathrm{wt} \%, 0.5 \mathrm{wt} \% \mathrm{Au} / \mathrm{BiVO}_{4}$ and $\mathrm{BiVO}_{4}$, respectively. The generated photocurrents increased with the contents of Au NPs, suggesting that the plasmonic absorption of $\mathrm{Au}$ NPs induced electrons excitation and resulted in the anodic photocurrents. 

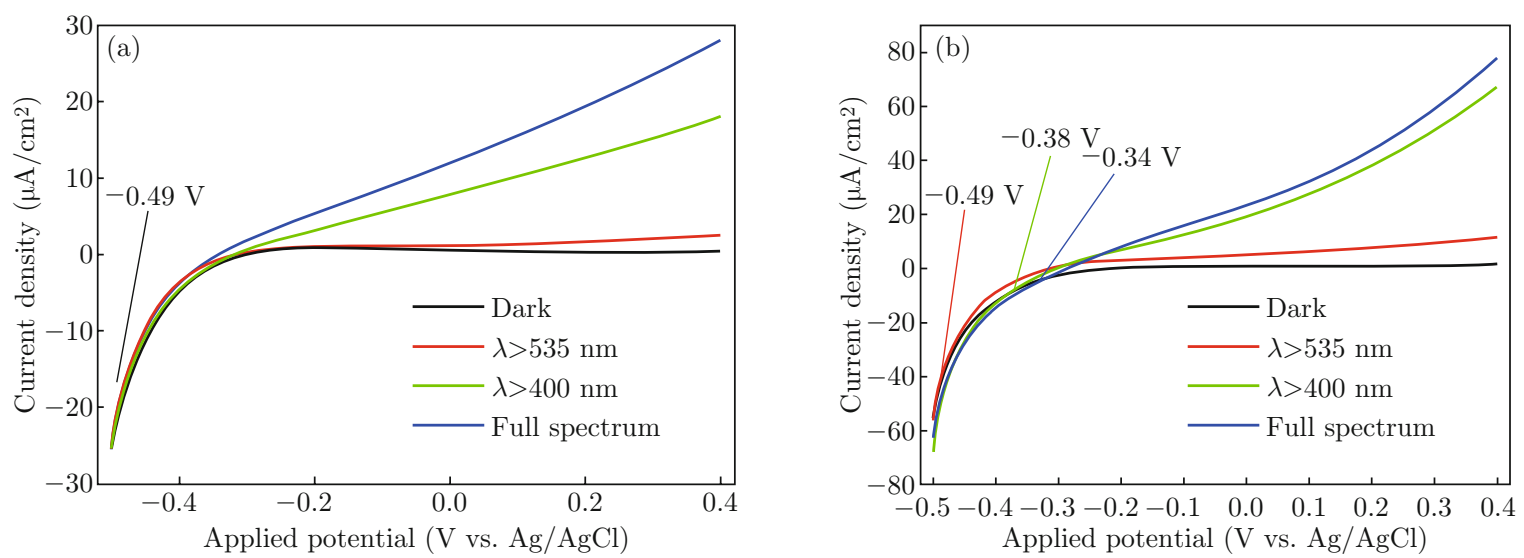

Fig. 4 Current density-potential curves of (a) $\mathrm{BiVO}_{4}$ and (b) 1 wt\% Au/BiVO 4 in $0.5 \mathrm{M} \mathrm{Na}_{2} \mathrm{SO}_{4}$ solution.
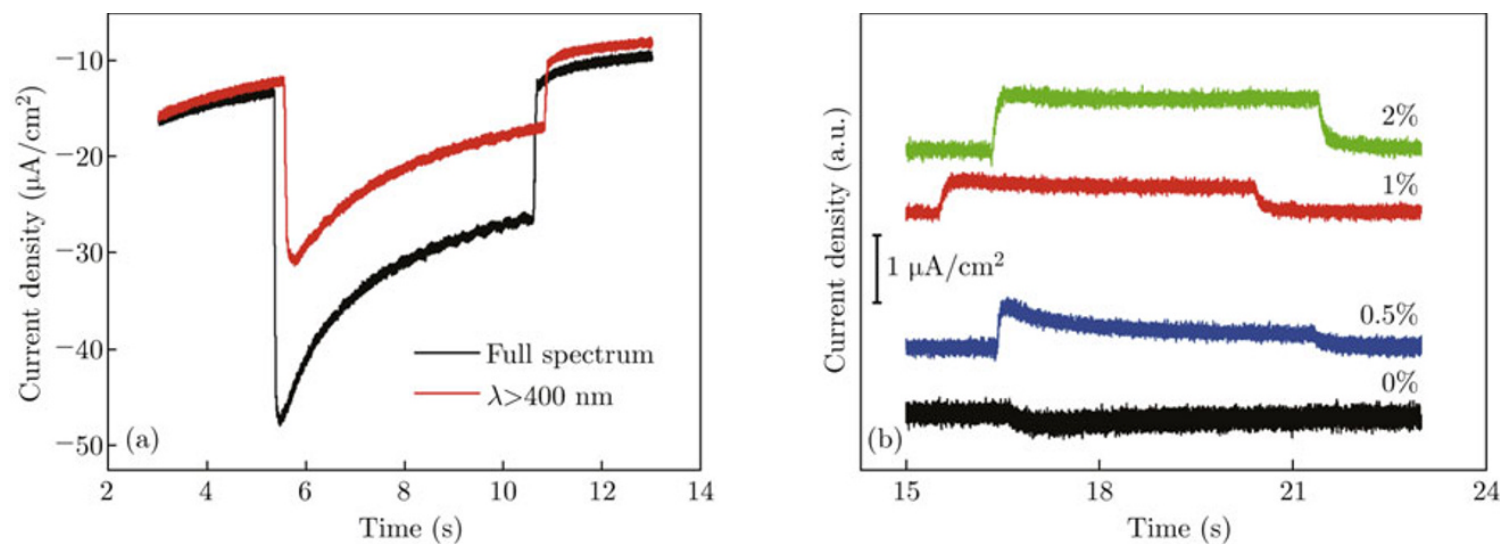

Fig. 5 Photocurrent transients of (a) $1 \mathrm{wt} \% \mathrm{Au} / \mathrm{BiVO}_{4}$ electrode under various illumination conditions at $-0.4 \mathrm{~V}$ vs. $\mathrm{Ag} / \mathrm{AgCl}$ bias and (b) $\mathrm{Au} / \mathrm{BiVO}_{4}$ electrodes with various $\mathrm{Au}$ contents under $\lambda>600 \mathrm{~nm}$ illumination at $0.2 \mathrm{~V}$ vs. $\mathrm{Ag} / \mathrm{AgCl}$ bias.

\section{Implications on the role of Au NPs}

The charge transfer schemes of $\mathrm{Au} / \mathrm{BiVO}_{4}$ electrode in various cases have been plotted in Fig. 6. Firstly, applying a more positive bias than $-0.34 \mathrm{~V}$ vs. $\mathrm{Ag} / \mathrm{AgCl}$ on the electrode (Fig. 6(a)), there is a more effective band bending at the interface of semiconductor $\left(\mathrm{BiVO}_{4}\right) /$ electrolyte. The photogenerated electrons would transfer faster to the conductive substrate and produce an anodic photocurrent, and simultaneously holes would migrate out from the valence band of $\mathrm{BiVO}_{4}$. In this case the electron transfer from the conduction band of $\mathrm{BiVO}_{4}$ to the Fermi level of gold NPs is not the main process. When upon irradiation with photon energy high enough to lead interband excitation of gold NPs from 5 d to 6 sp $[14,31,32]$, the Au NPs are electron sources but not electron sinks. It could be one reason for the enhanced anodic photocurrent of $\mathrm{Au} / \mathrm{BiVO}_{4}$ electrode. However, it is known that the strong interband absorption of Au NPs is below $400 \mathrm{~nm}[14,32]$. So it is not the reason for the enhanced anodic photocurrent upon $\lambda>400 \mathrm{~nm}$. Considering the Au NPs served as electron sources, the promoted charge separation and the inhibited surface recombination could be another reason for the enhanced photocurrent. The process that analogous p-n heterojunction for $\mathrm{Au} / \mathrm{BiVO}_{4}$ composite has also been described for the Pt modified $\mathrm{TiO}_{2}$ nanotubes [33].

When the applied bias is closed to the flat band of $\mathrm{BiVO}_{4}$, the band bending becomes small and the build in voltage decreased. Here the role of $\mathrm{Au}$ NPs as electron sinks is important. Photogenerated electrons would more rapidly transfer to Au NPs due to the Ohmic contact at the interface and the lower work function of $\mathrm{Au}$ (about $5.1 \mathrm{eV}$ [27]) compared with the conduction band of $\mathrm{BiVO}_{4}$. Simultaneously photogenerated holes would migrate from valence band of $\mathrm{BiVO}_{4}$ to the substrate, resulting in a cathodic photocurrent. Electrons trapped in the Au NPs would be consumed as they are active centers for water electrolysis [27]. When the energy of photons is high enough, the interband excitation of Au NPs occurs and the excited electrons transfer to the conduction band of $\mathrm{BiVO}_{4}$. Then the $\mathrm{Au} / \mathrm{BiVO}_{4}$ composite can also be deemed as a Z-scheme with a two-photon process. Although there are SPR absorption in the both illumination conditions 
in Fig. 6(a) and Fig. 6(b), it can be ignored because of its weak photocurrent response and low efficiency for photo(electro)catalytic reactions [22]. However, the SPR effect of Au NPs has to be considered in the third cases, as described in Fig. 6(c). Upon illumination with $\lambda>535 \mathrm{~nm}$, there is obvious anodic photocurrent for $\mathrm{Au} / \mathrm{BiVO}_{4}$ even at a bias closed to the flat band of $\mathrm{BiVO}_{4}$. The photocurrent response upon $\lambda>600 \mathrm{~nm}$ illumination can even be observed (Fig. 5(b)). The photocurrent is mainly originated from the plasmonic excitation of Au NPs. Due to the SPR effects, the intraband excitation of 6 sp electrons migrate to conduction band of $\mathrm{BiVO}_{4}$, which has a well electron-accepting property due to its high density of states, and then transfer to the conductive substrate under the build-in voltage, forming an anodic photocurrent. In this case water splitting should not take place due to the work function of $\mathrm{Au}$ is not enough for water oxidation. However, the potential originated from the band bending of $\mathrm{BiVO}_{4}$ is powerful enough to drive electrons flowing, so as to produce anodic photocurrents. $\mathrm{U}_{\text {on }}$ of $\mathrm{Au} / \mathrm{BiVO}_{4}$ with illumination $\lambda>535 \mathrm{~nm}$ is close to that of the $\mathrm{BiVO}_{4}$ proof above process. According to above analysis, it can be expected to employ Au NPs as electron sources or sinks for photoexcitation process by controllable wavelength and applied potential, which is applicable in the selective photocatalytic reaction, light-driven logic gates and so on [34].

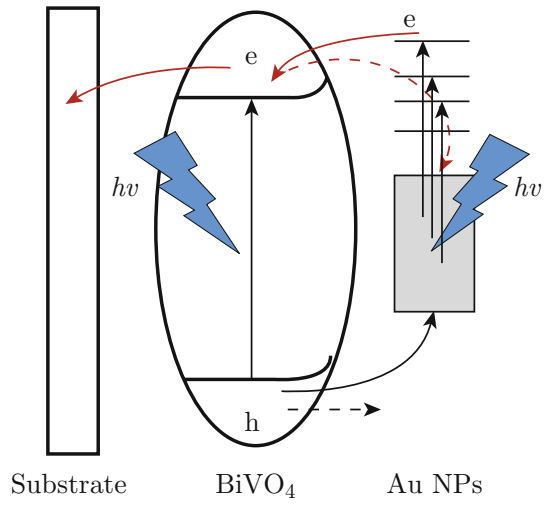

(a)

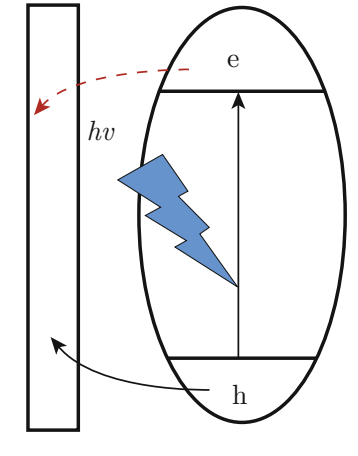

$\mathrm{BiVO}_{4}$

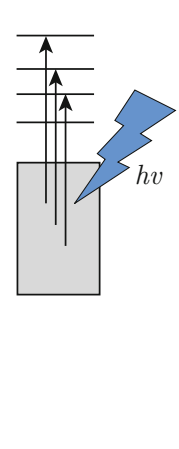

$\mathrm{Au}$ NPs

(b)

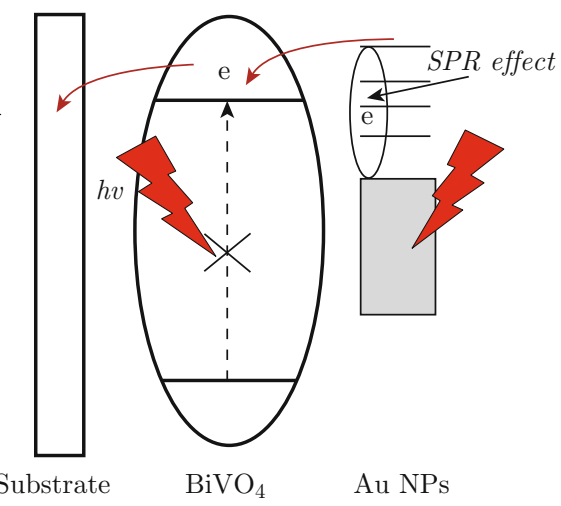

(c)

Fig. 6 Simplified scheme of the primary processes occurring upon excitation of an $\mathrm{Au} / \mathrm{BiVO}_{4}$ electrode. ((a): bias $>-0.34 \mathrm{~V}$; (b): $\lambda<535 \mathrm{~nm}$, bias $<-0.34 \mathrm{~V}$; (c): $\lambda>535 \mathrm{~nm})$.

\section{Conclusion}

$\mathrm{Au}$ modified $\mathrm{BiVO}_{4}$ has been synthesized by deposition precipitation urea method. The highly crystallized $\mathrm{Au}$ nanoparticles with a size of $8 \sim 10 \mathrm{~nm}$ dispersed on the surface of $\mathrm{BiVO}_{4}$ particles. Stable metallic gold has been proofed by XANES. The SPR absorption of $\mathrm{Au}$ NPs has been analyzed by DRS. Enhanced photocatalytic and photoelectrochemical performance for $\mathrm{Au} / \mathrm{BiVO}_{4}$ has been observed by the phenol degradation and anodic photocurrent measurements. The changes of photocurrent onset potential and photocurrent transient under various illumination conditions indicated different charge transfer processes and a complicate role of Au NPs. The SPR effect is negligible on the photocatalytic but observable by photocurrent measurements. The controllable role of Au NPs as electron sources or sinks by wavelength and applied potentials is important for photoexcitation physical or chemical processes.

\section{Acknowledgment}

The research is financially supported by National
Natural Science Foundation of China (No. 20907031), the SSRF project (No. 10sr0175), and Natural Science Foundation of Shanghai (No. 09ZR1414800). The authors are grateful to Wei Li of the Instrumental Analysis Center of Shanghai Jiao Tong University for SEM measurements.

\section{References}

[1] M. C. Long, J. Cai, W. M. Cai, H. Chen and X. Chai, Prog. Chem. 18, 1065(2006).

[2] R. V. D. Krol, Y. Liang and J. Schoonman, J. Mater. Chem. 18, 2311 (2008). http://dx.doi.org/10.1039/ b718969a

[3] S. S. Rayalu and N. K. Labhsetwar, Int. J. Nanotechnol. 7, 967 (2010). http://dx.doi.org/10.1504/ IJNT . 2010.034702

[4] M. C. Long, W. M. Cai, J. Cai, B. X. Zhou, X. Y. Chai and Y. H. Wu, J. Phys. Chem. B 110, 20211 (2006). http://dx.doi.org/10.1021/jp063441z

[5] J. Q. $\mathrm{Yu}$ and A. Kudo, Adv. Funct. Mater. 16, 2163 (2006). http://dx.doi.org/10.1002/adfm. 200500799

[6] S. Kohtani, S. Makino, A. Kudo, K. Tokumura, Y. Ishigaki, T. Matsunaga, O. Nikaido, K. Hayakawa and 
R. Nakagaki, Chem. Lett. 31, 660 (2002). http://dx. doi.org/10.1246/cl.2002.660

[7] H. X. Li, Z. F. Bian, J. Zhu, Y. N. Huo, H. Li and Y. F. Lu, J. Am. Chem. Soc. 129, 4538 (2007). http:// dx.doi.org/10.1021/ja069113u

[8] A. P. Zhang and J. Z. Zhang, J. Alloy Compd. 491, 631 (2010).

[9] Y. Xie, K. Ding, Z. Liu, R. Tao, Z. Sun, H. Zhang and G. An, J. Am. Chem. Soc. 131, 6648(2009). http:// dx.doi.org/10.1021/ja900447d

[10] G. H. Li and K. A. Gray, Chem. Phys. 339, 173 (2007). http://dx.doi.org/10.1016/j.chemphys . 2007.05 .023

[11] E. Ozbay, Science 311, 189 (2006). http://dx.doi. org/10.1126/science. 1114849

[12] Y. Tian and T. Tatsuma, Chem. Commun. 1810 (2004). http://dx.doi.org/10.1039/b405061d

[13] Y. Tian and T. Tatsuma, J. Am. Chem. Soc. 127, 7632(2005). http://dx.doi.org/10.1021/ja042192u

[14] H. Y. Zhu, X. Chen, Z. F. Zheng, X. B. Ke, E. Jaatinen, J. C. Zhao, C. Guo, T. F. Xie and D. J. Wang, Chem. Commun. 7524 (2009). http://dx.doi.org/ 10. 1039/b917052a

[15] A. Furube, L. Du, K. Hara, R. Katoh and M. Tachiya, J. Am. Chem. Soc. 129, 14852 (2007). http://dx.doi. org/10.1021/ja076134v

[16] X. Chen, H. Y. Zhu, J. C. Zhao, Z. F. Zheng and X. P. Gao, Angew. Chem. Int. Ed. 47, 5353 (2008). http:// dx.doi.org/10.1002/anie. 200800602

[17] E. Kowalska, R. Abe and B. Ohtani, Chem. Commun. 241 (2009). http://dx.doi.org/10.1039/b815679d

[18] S. Naya, A. Inoue and H. Tada, J. Am. Chem. Soc. 132, 6292 (2010). http://dx.doi.org/10.1021/ja101711j

[19] P. Wang, B. Huang, X. Qin, X. Zhang, Y. Dai, J. Wei and M. H. Whangbo, Angew. Chem. Int. Ed. 47, 7931(2008). http://dx.doi.org/10.1002/anie. 200802483

[20] C. Hu, T. Peng, X. Hu, Y. Nie, X. Zhou, J. Qu and H. He, J. Am. Chem. Soc. 132, 857(2010). http://dx . doi.org/10.1021/ja907792d
[21] V. Schwartz, D. R. Mullins, W. Yan, B. Chen, S. Dai and S. H. Overbury, J. Phys. Chem. B 108, 15782 (2004). http://dx.doi.org/10.1021/jp048076v

[22] P. Chatchai, S. Y. Kishioka, Y. Murakami, A. Y. Nosaka and Y. Nosaka, Electrochim. Acta 55, 592 (2010). http://dx.doi.org/10.1016/j.electacta. 2009.09.032

[23] R. Zanella, S. Giorgio, C. R. Henry and C. Louis, J. Phys. Chem. B 106, 7634 (2002). http://dx.doi.org/ 10.1021/jp0144810

[24] S. Link and M. A. El-Sayed, J. Phys. Chem. B 103, 4212 (1999). http://dx.doi.org/10.1021/jp984796o

[25] A. Galembeck and O. L. Alves, Thin Solid Films 365, 90 (2000). http://dx.doi.org/10.1016/ S0040-6090 (99) 01079-2

[26] K. Teramura, K. Maeda, T. Saito, T. Takata, N. Saito, Y. Inoue and K. Domen, J. Phys. Chem. B 109, 21915 (2005). http://dx.doi.org/10.1021/jp054313y

[27] A. Shiga, A. Tsujiko, T. Ide, S. Yae and Y. Nakato, J. Phys. Chem. B 102, 6049 (1998). http://dx.doi. org/10.1021/jp981280w

[28] M. Long, W. Cai and H. Kisch, J. Phys. Chem. C 112, 548 (2008). http://dx.doi.org/10.1021/jp075605x

[29] R. Beranek and H. Kisch, Electrochem. Commun. 9, 761 (2007). http://dx.doi.org/10.1016/j.elecom. 2006.11.011

[30] L. M. Peter, Chem. Rev. 90, 753 (1990). http://dx. doi.org/10.1021/cr00103a005

[31] K. Yamada, K. Miyajima and F. Mafune, J. Phys. Chem. C 111, 11246 (2007). http://dx.doi.org/10. 1021/jp0730747

[32] B. Balamurugan and T. Maruyama, Appl. Phys. Lett. 87, 143105 (2005). http://dx.doi.org/10.1063/1. 2077834

[33] Y. Chen, J. C. Crittenden, S. Hackney, L. Sutter and D. W. Hand, Environ. Sci. Techol. 39, 1201(2005). http://dx.doi.org/10.1021/es049252g

[34] M. C. Long, R. Beranek, W. M. Cai and H. Kisch, Electrochim. Acta 53, 4621 (2008). http://dx.doi. org $/ 10.1016 / \mathrm{j}$.electacta. 2008.01.077 